\title{
EFFECTS OF THE 1988 WILDFIRES ON STREAM SYSTEMS of Yellowstone National PARK
}

\author{
G. WAYNE MINSHALL $\bullet$ CHRISTOPHER T. ROBINSON \\ STREAM ECOLOGY CENTER $\downarrow$ DEPARTMENT OF BIOLOGICAL SCIENCES \\ IDAHO STATE UNIVERSITY • POCATELLO
}

\section{$\checkmark \quad$ INTRODUCTION}

The recovery of stream ecosystems in Yellowstone National Park following the fires of 1988 has been punctuated by disturbances caused by high flows in 1991 and again in 1992. In at least a third of the study sites, changes in channel conditions in 1992 were equal or greater than those documented in the preceding year. These impacts are expected to translate into reductions in primary production, benthic organic matter, and macroinvertebrate abundance and diversity over the next few years in most of streams draining burned watersheds in and adjacent to the Park. However, in Cache Creek and its tributaries the changes are so profound that recovery of biotic structure and function to prefire or reference stream conditions are unlikely to occur in succeeding decades or even centuries. Comparison of conditions in Cache Creek with those in other, less severely impacted watersheds in subsequent years could provide valuable insights into the differences in ecosystem response to severe versus moderate disturbance following fire or other comparable impacts such as overgrazing or climate change. The changes which occurred in Cache Creek in 1992 are expected to result in much reduced rates of recovery in ecosystem structure and function and possibly to the establishment of new (lowered) equilibrium conditions. Although such a possible outcome has been postulated (Minshall et al. 1989), the ideas have never been tested. Examination of additional streams, coupled with analysis using Geographical Information System (GIS), would permit determination of whether the adverse effects seen in
Cache Creek are widespread or limited to only a few drainages and whether they are in the normal range of conditions or have been magnified as a result of fire suppression or other factors.

\section{- OVerall Progress}

Various collections and measurements were made in October 1988, August 1989, 1990, 1991, and 1992 at 18 burn and 4 reference sites and in March 1989 at 12 of the burn and 1 of the reference sites under support from the National Science Foundation and the U.S. Fish and Wildlife Service. Most of the study sites are on high gradient "mountain trout streams" located in the northern portion of Yellowstone National Park and receive substantial runoff from snowmelt. However, Fairy and 3rd order Iron Springs Creeks, in the Old Faithful area, are low gradient and receive large inputs from groundwater, including geothermal sources. Complete results prior to the 1991 sampling period can be found in the 1991 annual report (Minshall et al. 1992). With a few minor exceptions (e.g., the recording thermometers at a few sites were broken or missing) all the information specified in the research proposal was obtained. Adverse weather conditions or "bear closures" prevented the assessment of all 22 sites in March 1989.

Most of the physical and all of the chemical determinations of the data have been completed through the tabulation and initial statistical or graphical analyses, except for the time-consuming 
assessment of woody debris densities from field drawn maps. The processing of all periphyton samples (chlorophyll a, AFDM, and B/C ratio's) will be completed by the end of November 1992. All transported organic matter (TOM) samples for 1992 have been processed for AFDM determinations and qualitatively characterized for type of organic matter. These data are summarized graphically in this report. As usual, the processing of benthic macroinvertebrate samples (110 samples for 1992) and associated benthic organic matter (BOM) is only partially complete at this time. The processing of these samples is time consuming, averaging 5 hours per sample.

\section{$\checkmark \quad$ RESUltS AND DISCUSSION}

\section{PHYSICAL AND CHEMICAL RELATIONSHIPS}

Channel cross-sections: Some of the most substantial changes in stream channel morphology observed during this study occurred in 1992. For example, the 1st order sites of Cache and Twin Creeks displayed major changes in channel crosssections for 1992. Although, low gradient 1st order streams, e.g., Fairy Creek and the reference site Rose Creek, again showed essentially no change in channel cross-section shape in 1992.

For 2nd order streams, major channel changes, again, were documented in Upper Cache Creek. The debris dam that formed downstream of the representative transect in Blacktail Deer Creek in 1991 was retained in 1992 and maintained flow in the new side-channel. No channel cross-section changes were observed for low gradient 2nd order Fairy and Iron Springs Creeks or the reference Amphitheater Creek.

Major channel cross-section changes occurred in 3rd order Cache Creek, and especially in south Fork Cache Creek. Many large woody debris dams were eliminated from South Fork Cache Creek. Third Order Cache Creek experienced more channel widening and the main channel continued to shift from the left side of the stream to the right side. Again, little change was observed in low gradient 3rd order streams, i.e., Iron Springs Creek and the reference Pebble Creek in 1992. Lava Creek also displayed little cross-section change due to its highly confined channel. Compared to the smaller streams, 4th order sites displayed little channel change in
1992. Of 4th order sites, Hellroaring Creek showed the greatest channel change.

Temperature: Minimum stream temperatures remained essentially unchanged at all burn and reference sites. These data suggest that the fires had no effect on low temperatures. However, our measurements do not provide information on the duration of the cold period, which might be expected to increase with the removal of protective tree cover. Maximum stream temperatures in small burn streams have remained elevated relative to small reference streams through 1992. Larger streams (3rd and 4th order) impacted by the 1988 fires have displayed similar temperature regimes as large reference streams. The higher temperatures in small burn streams resulted in greater annual temperature ranges (Delta-T) for these streams relative to reference streams.

Percent embeddedness: Mean embeddedness of large substrates by sand and silt decreased in 1st order burn streams from about $60 \%$ in 1988 to about $30 \%$ in 1989 then increased slightly to about $50 \%$ by 1992. Little change was observed in 2nd order burn streams among years. Mean embeddedness doubled in 1989 from 1988 values for 3rd order burn streams then decreased to 1988 values in 1990, and increased again in 1991 and 1992. Embeddedness remained unchanged in 4th order burn sites until 1990 then increased dramatically in 1991 and decreased in 1992. No change in mean embeddedness was observed among years in 2nd order reference streams. Third order reference streams showed much temporal variation in embeddedness. These data suggest a pulse of fine sediments moved from smaller burn streams into and out of larger burn streams over time.

Substrata: A decrease in mean substrate size over time indicates input of fine sediments within a study reach. Mean substrate size either decreased or remained unchanged in burn streams following 1988 (Table 1). No changes were observed in mean substrate size for 2 nd and 3rd order reference streams. In general, substrate CV (Coefficient of Variation) was much higher in burn streams than reference streams during the study period. Substrate CV remained unchanged, but relatively high, in smaller burn sites among years (Table 1). Substrate $\mathrm{CV}$ tended to be lower in larger burn streams and reference streams. 
Table 1. Mean velocities, depths, and substrate $\mathrm{x}$-axis with respective coefficients of variation (CV) for the Yellowstone National Park fire Study Sites. Sample size equals 100 except for dates with asterisk.

\begin{tabular}{|c|c|c|c|c|c|c|c|c|c|}
\hline Stream & Order & Date & $\begin{array}{l}\text { velocity } \\
(\mathrm{m} / \mathrm{s})\end{array}$ & $\begin{array}{c}\text { CV } \\
\text { velocity }\end{array}$ & $\begin{array}{r}\text { depth } \\
(\mathrm{cm})\end{array}$ & $\begin{array}{c}\text { CV } \\
\text { depth }\end{array}$ & $\begin{array}{c}x \text {-axis } \\
\text { (cm) }\end{array}$ & $\begin{array}{c}C V \\
x \text {-axis }\end{array}$ & \\
\hline \multirow[t]{5}{*}{ Blacktail, E. Fork } & 1 & $11 / 88$ & 0.15 & 1.88 & 15.2 & 0.67 & 18.0 & 1.20 & \\
\hline & & $8 / 89$ & 0.26 & 0.89 & 11.9 & 0.66 & 13.7 & 1.51 & \\
\hline & & $8 / 90$ & 0.31 & 0.73 & NA & NA & 9.1 & 1.43 & \\
\hline & & $8 / 91$ & 0.37 & & 12.5 & & 8.2 & 0.96 & \\
\hline & & $8 / 92$ & 0.20 & 1.12 & 11.3 & 0.62 & 4.9 & 1.39 & \\
\hline \multirow[t]{5}{*}{ Blacktail, W. Fork } & 1 & $11 / 88$ & 0.17 & 1.16 & 13.0 & 0.65 & 12.6 & 1.45 & \\
\hline & & $8 / 89$ & 0.16 & 0.83 & 14.4 & 0.59 & 14.2 & 1.18 & \\
\hline & & $8 / 90$ & 0.19 & 0.95 & NA & NA & 15.5 & 1.15 & \\
\hline & & $8 / 91$ & 0.18 & & 18.3 & & 14.0 & 1.24 & \\
\hline & & $8 / 92$ & 0.08 & 0.79 & 18.2 & 0.59 & 18.8 & 1.02 & \\
\hline \multirow[t]{5}{*}{ Upper Cache } & 1 & $11 / 88$ & 0.04 & 1.02 & 6.2 & 0.64 & 10.7 & 1.36 & \\
\hline & & $8 / 89$ & 0.15 & 0.88 & 3.8 & 0.68 & 5.5 & 1.90 & $\cdots$ \\
\hline & & $8 / 90$ & 0.12 & 0.74 & NA & NA & 5.5 & 1.42 & \\
\hline & & $8 / 91$ & 0.12 & & 5.4 & & 6.4 & 2.49 & \\
\hline & & $8 / 92$ & 0.18 & 1.03 & 9.2 & 0.48 & 8.1 & 1.07 & \\
\hline \multirow[t]{5}{*}{ Fairy } & 1 & $11 / 88$ & 0.25 & 0.57 & 21.4 & 0.55 & 0.8 & 2.11 & \\
\hline & & $8 / 89$ & 0.29 & 0.46 & 22.6 & 0.41 & 1.2 & 1.63 & \\
\hline & & $8 / 90$ & 0.53 & 0.49 & NA & NA & 1.1 & 0.98 & \\
\hline & & $8 / 91$ & 0.28 & & 27.7 & & 0.7 & 1.13 & \\
\hline & & $8 / 92$ & 0.17 & 0.68 & 25.9 & 0.33 & 0.9 & 2.16 & \\
\hline \multirow[t]{5}{*}{ Twin } & 1 & $11 / 88$ & 0.11 & 1.83 & 12.1 & 0.77 & 21.5 & 1.03 & \\
\hline & & $8 / 89$ & 0.21 & 1.44 & 15.6 & 0.66 & 18.8 & 0.72 & \\
\hline & & $8 / 90$ & 0.39 & 0.95 & NA & NA & 20.5 & 1.13 & \\
\hline & & $8 / 91$ & 0.08 & & 12.9 & & 20.8 & 1.04 & \\
\hline & & $8 / 92$ & 0.12 & 1.35 & 16.1 & 0.65 & 14.4 & 1.21 & \\
\hline \multirow[t]{5}{*}{ Lower Cache } & 2 & $11 / 88 *(86)$ & 0.18 & 1.46 & 11.3 & 0.57 & 18.1 & 1.05 & \\
\hline & & $8 / 89$ & 0.33 & 0.84 & 18.4 & 0.63 & 16.5 & 1.26 & \\
\hline & & $8 / 90$ & 0.33 & 0.83 & NA & NA & 16.2 & 1.29 & \\
\hline & & $8 / 91$ & 0.25 & & 9.4 & & 9.7 & 1.37 & \\
\hline & & $8 / 92$ & 0.20 & 0.97 & 9.5 & 0.46 & 10.4 & 1.20 & \\
\hline \multirow[t]{5}{*}{ Upper Cache } & 2 & $11 / 88$ & 0.11 & 1.59 & 9.1 & 0.61 & 10.8 & 0.89 & \\
\hline & & $8 / 89$ & 0.16 & 0.77 & 8.9 & 0.66 & 8.1 & 1.59 & \\
\hline & & $8 / 90$ & 0.23 & 0.81 & NA & NA & 7.6 & 1.00 & \\
\hline & & $8 / 91$ & 0.18 & & 9.1 & & 7.2 & 1.30 & \\
\hline & & $8 / 92$ & 0.27 & 1.02 & 10.7 & 0.47 & 8.5 & 0.97 & \\
\hline \multirow[t]{5}{*}{ Fairy } & 2 & $11 / 88$ & 0.07 & 0.56 & 7.2 & 0.67 & 8.7 & 2.09 & \\
\hline & & $8 / 89 *(50)$ & 0.21 & 0.64 & 7.3 & 0.36 & 6.5 & 0.64 & \\
\hline & & $8 / 90$ & 0.25 & 0.37 & NA & NA & 8.3 & 0.75 & \\
\hline & & $8 / 91$ & 0.27 & & 25.6 & & 0.5 & 2.59 & \\
\hline & & $8 / 92$ & 0.10 & 0.78 & 24.2 & 0.46 & 0.9 & 1.56 & \\
\hline \multirow[t]{5}{*}{ Iron Springs } & 2 & $11 / 88$ & 0.22 & 0.81 & 16.0 & 0.52 & 0.9 & 2.03 & \\
\hline & & $8 / 89 *(50)$ & 0.26 & 0.78 & 22.6 & 0.46 & 0.6 & 1.77 & \\
\hline & & $8 / 90$ & 0.24 & 0.71 & NA & NA & 0.9 & 1.47 & \\
\hline & & $8 / 91$ & 0.10 & & 13.1 & & 5.1 & 1.35 & \\
\hline & & $8 / 92$ & 0.28 & 1.15 & 12.4 & 0.47 & 5.9 & 2.04 & \\
\hline \multirow[t]{5}{*}{ Blacktail Main } & 2 & $11 / 88$ & 0.39 & 1.11 & 10.4 & 0.58 & 11.5 & 0.88 & \\
\hline & & $8 / 89 *(64)$ & 0.37 & 0.72 & 12.6 & 0.72 & 5.0 & 0.74 & \\
\hline & & $8 / 90$ & 0.40 & 0.77 & NA & NA & 7.3 & 0.99 & \\
\hline & & $8 / 91$ & 0.34 & & 21.1 & & 15.6 & 1.01 & \\
\hline & & $8 / 92$ & 0.16 & 1.14 & 17.2 & 0.59 & 16.1 & 0.97 & \\
\hline
\end{tabular}


Table 1. (cont.)

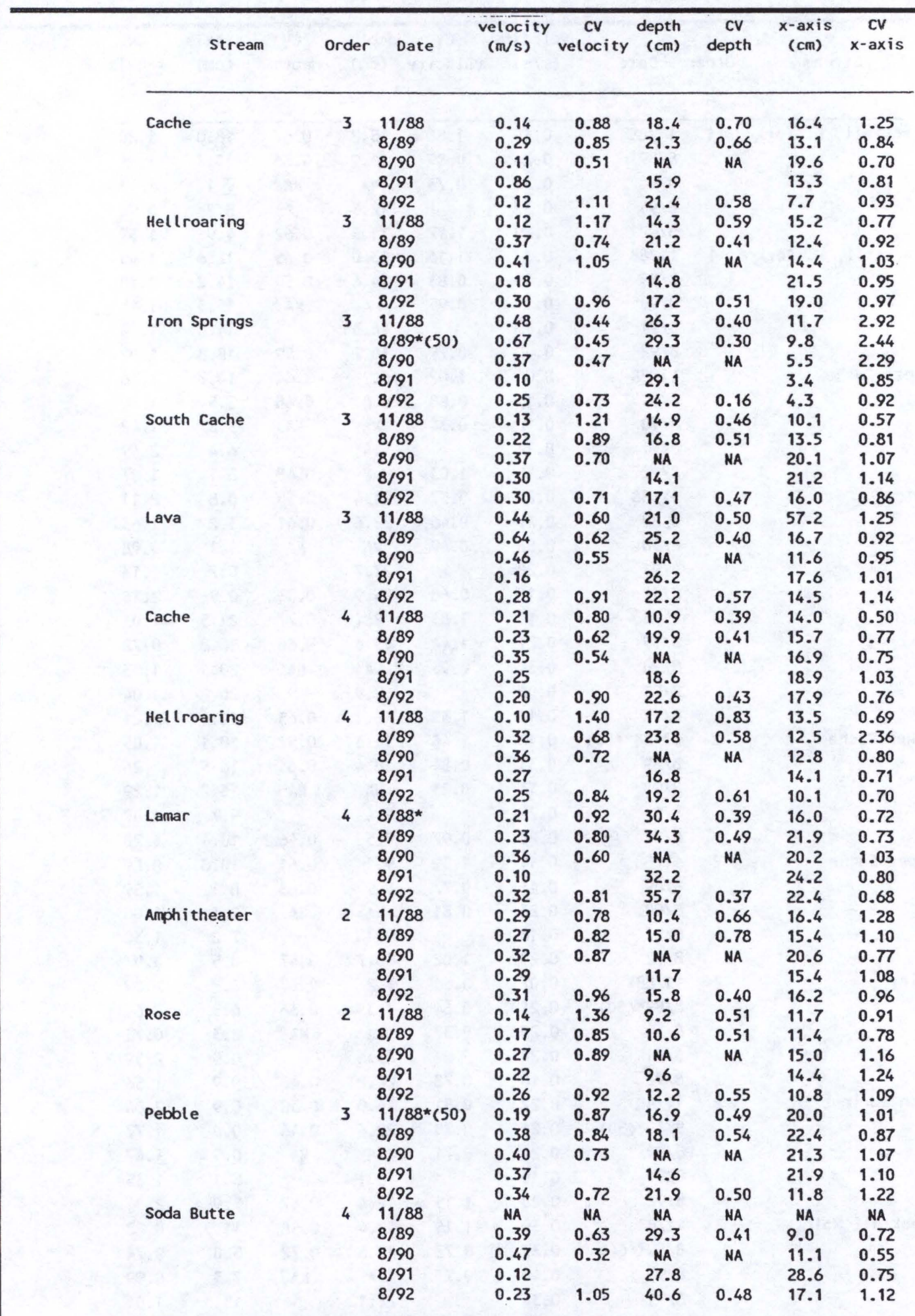

* $n=34$ for velocity, $n=99$ for other measures 
Velocity: Changes in velocity reflect changes in channel morphology and complexity, and flow dynamics. Mean velocities in 1992 were similar to 1991 values in most burn and reference streams (Table 1). In contrast, the coefficient of variation (CV) for velocity increased between years in 1st and 2nd order burn streams suggesting less uniform habitat conditions in 1992, while remaining unchanged in reference streams of comparable size. The CV for velocity remained unchanged or increased in 1992 in 3rd order burn sites, and remained unchanged in 3rd order reference sites. Mean velocities were similar in 1992 to 1991 values in 4th order burn sites (Table 1). Here, the CV of velocity increased slightly from 1991 to 1992 . The 4th order reference site was moved further upstream in 1991. Although little change was observed in 1992 in mean velocities at this site, the CV of velocity increased reflecting the more diverse habitat conditions at the new location.

Depth: Changes in channel depth reflect erosion or filling of stream channels by fine sediments with corresponding changes in $\mathrm{CV}$ reflecting the diversity or complexity of channel habitats. Little change was observed in mean depth or CV of depth for burn streams among years (Table 1). No changes in mean depth or depth CV were observed in 2nd and 3rd order reference streams. Mean depth increased in the 4th order reference site reflecting the change in channel location.

Water chemistry: Water grab-samples were collected each year during the time of benthic sampling. Field measured $\mathrm{pH}$ values essentially remained unchanged between 1991 and 1992 for most sites. Third order Cache and SF Cache Creeks decreased in pH in 1992 from 1991 values. The other 3rd order burn sites displayed no change in $\mathrm{pH}$. Values for $\mathrm{pH}$ remained relatively constant for reference sites.

Specific conductance decreased from 1988 to 1990 in most 1st and 2nd order burn sites, typically by $0.5 x$, followed by slight increases in 1991 and 1992. The main exceptions were those streams receiving large inputs of groundwater. For example, Fairy and Iron Springs Creeks displayed the least amount of change among years for 1st and 2 nd order burn sites. Second order Fairy Creek displayed values 4-6x higher than 1st order Fairy Creek due to geothermal inputs. First and 2nd order sites displayed higher among stream variation in contrast to 3rd and 4th order burn sites. Third and 4th order burn sites displayed little change among years. Reference sites displayed similar patterns as burn sites, although little change was found in Amphitheater Creek among years.

Total hardness was much more variable in smaller 1st and 2nd order burn sites than in 3rd and 4th order burn sites. However, no temporal trends in hardness were observed in burn sites. Indeed, more temporal variation was observed in Rose and Soda Butte reference sites than in burn sites.

Total alkalinity decreased continuously in 1st order Twin and Lamar River and decreased slightly in Upper and Lower 2nd order Cache Creeks following 1988. However, little change was evident for most burn sites regardless of size. Alkalinity either increased in 1992 or remained unchanged among years in reference streams.

Ortho-phosphate levels indicated several trends among burn streams, while no change was evident in reference sites for 1992. No change among years was evident for Fairy, Iron Springs, and Lava Creeks. Ortho-phosphate levels increased in most other burn sites in 1989 from 1988 values then subsequently decreased and stabilized in 1990 through 1992. As with the other water parameters, the most variation among sites occurred in 1st and 2 nd order burn sites, with 3rd and 4th order burn sites exhibiting similar values.

Ammonium values showed little difference among years at many of the burn sites, although values increased in 1991 and remained elevated in 1992 for most smaller burn sites. First order burn sites, 2nd order Blacktail Deer Creek, and Iron Springs Creek exhibited the least change among years. Some burn sites exhibited increases in 1990, while increases in ammonium levels did not occur until 1991 and decreased in 1992 in reference sites.

In contrast to ammonium values, nitrate values tended to increase in most burn sites by 1989 and remain high through 1992. Nitrate levels were consistently low in the reference sites among years. As with the other chemical variables, little change was observed in nitrate levels among years for Fairy and Iron Springs Creeks. Most change was observed for the Cache Creek sites. 


\section{BIOLOGICAL RELATIONSHIPS}

Transported organic matter: Transported organic matter was sampled and quantified in two size categories: Coarse (CPOM) and Fine (FPOM) particulate organic matter. This material also was characterized qualitatively with the percent charcoal data presented in this report. CPOM levels increased in all burn sites in 1991 from previous years, and remained unchanged in 1992 (Figure 1). CPOM levels also were higher in 1992 in reference sites resulting from a high amount of filamentous algae. As with CPOM values, FPOM values dramatically increased in burn streams in 1991 and 1992 (Figure 1). FPOM values also increased in reference streams in 1992. The higher values in 1991 over previous years for both CPOM and FPOM may be attributed to higher overall flows and respective flow events. The percent CPOM consisting of charcoal decreased substantially in 1992 in the burn streams (Figure 2). The percent charcoal remained low in reference streams. The percent charcoal of FPOM also decreased in 1992 in burn streams and remained low in reference streams.

\section{WORK TO BE PERFORMED DURING REMAINING REPORTING PERIOD}

As noted above, most of the benthic macroinvertebrate and associated organic matter samples still need to be processed. These samples are expected to be completed by the end of January 1993. In addition, analyses of woody debris densities and mapping should be completed at that time. Work also will be continued on statistical and graphical analysis of the data.

\section{- LITERATURE CITED}

Minshall, G. W., J. T. Brock, and J. D. Varley. 1989. Wildfires and Yellowstone's stream ecosystems: a temporal perspective shows that aquatic recovery parallels forest succession. BioScience 39:707-715.

Minshall, G. W., and C. T. Robinson. 1992. Effects of the 1988 wildfires on stream systems of Yellowstone National Park, 1991. Annual Report to the National Park Service. 48 p. 


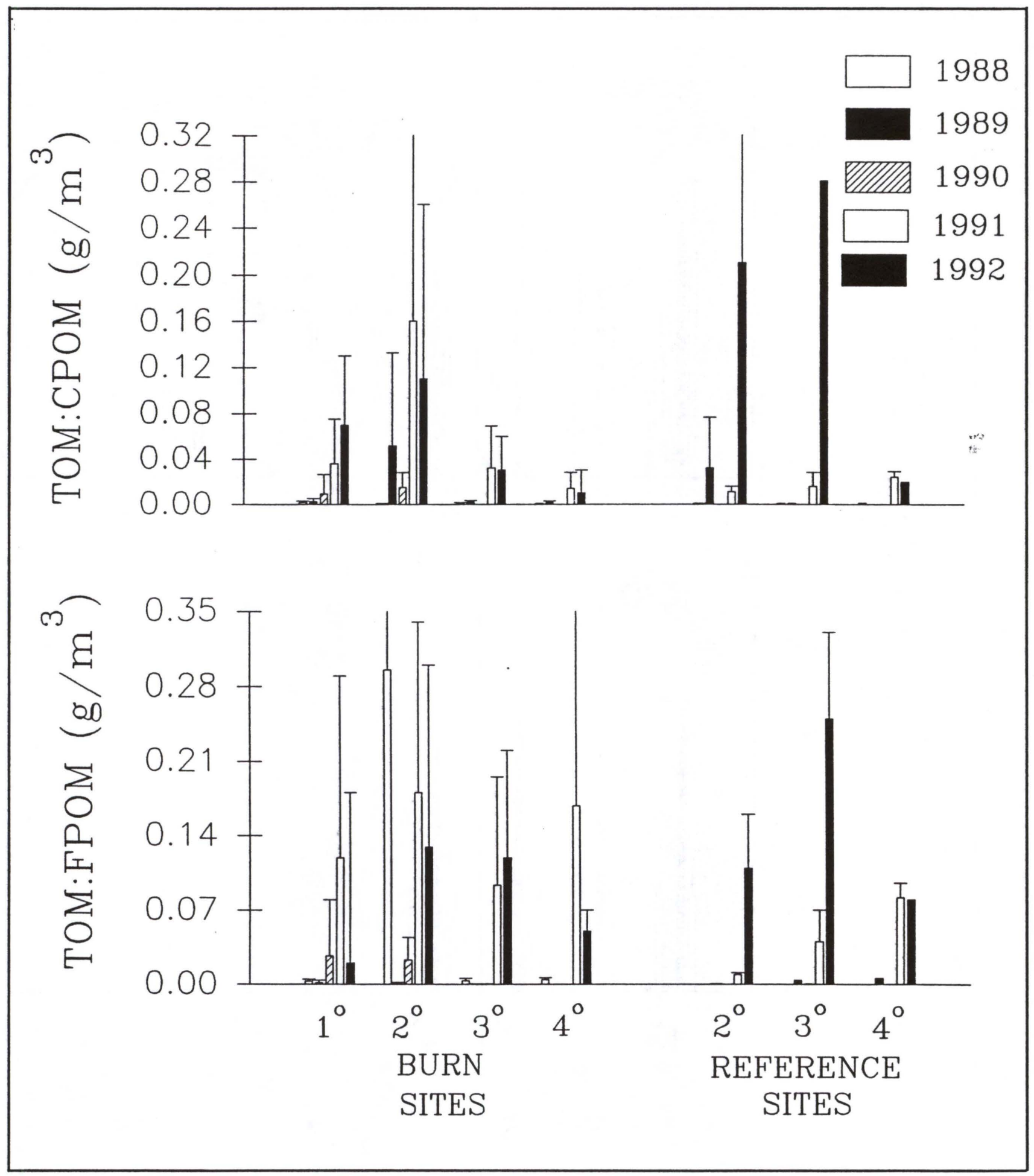

Figure 1. Transported organic matter $\left(\mathrm{g} / \mathrm{m}^{3}\right)$ as coarse $(\mathrm{CPOM})$ or fine $(\mathrm{FPOM})$ particulate organic matter in burn and reference streams. Bars represent $+1 \mathrm{SD}$. Sample size equals five sites (2 samples/site/category) for 1st, 2nd, and 3rd order burn streams, 3 sites for 4th order burn, 2 sites for 2 nd order reference, and 1 site each for 3rd and 4 th order reference streams. 


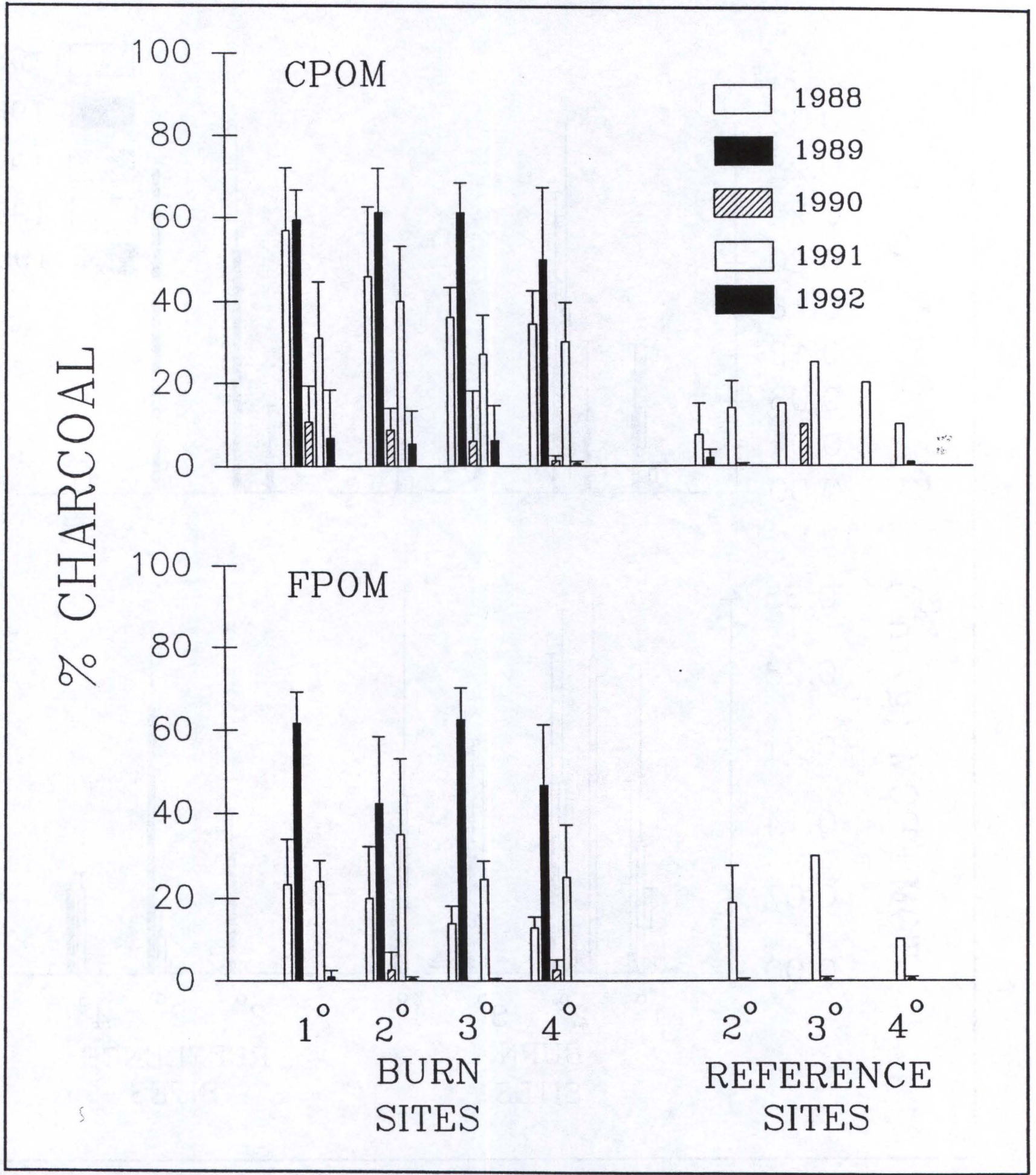

Figure 2. The percent charcoal comprising transported organic matter in CPOM and FPOM. Bars represent +1 standard deviation of the mean. 